\title{
A Finite Element Model of Propagation on the Southern and Western Australian Continental Shelf
}

\author{
Marcia J. Isakson and Nicholas P. Chotiros \\ Applied Research Laboratories \\ The University of Texas \\ Austin, Texas 78713 \\ Email: misakson@arlut.utexas.edu
}

\begin{abstract}
Much of the littoral region of Southern and Western Australia is composed of a soft limestone bed covered by a layer of unconsolidated sand [2]. The limestone bed, composed of calcarenite, has a high shear wave speed and there is often efficient coupling between the water born wave and the shear mode. Although studies of the effect of the elastic mode in the calcarenite on transmission loss have been undertaken, the effects of the thin sand layer and interface roughness must be quantified in order to determine a robust inversion scheme. It is found that a $1.0 \mathrm{~m}$ sand layer decreases the transmission loss by more than $5 \mathrm{~dB}$ while a $2.5 \mathrm{~m}$ layer can decrease the loss by as much as $20 \mathrm{~dB}$. Interface roughness affects higher frequencies by increasing transmission loss and a rough interface waveguide with a sand layer can have a similar level of transmission loss as a waveguide with a bare calcarenite bottom. However, the frequency dependence and model interference patterns of the two waveguides are different. An inversion scheme based on a bare calcarenite model which would lead incorrect results.
\end{abstract}

\section{INTRODUCTION}

Most of the Southern and Western Australian continental shelf is characterized by a thin unconsolidated sand layer over a limestone cap [2]. The limestone has a very high shear wave speed of $1200-1400 \mathrm{~m} / \mathrm{s}$ and a compressional wave speed of $2400-2800 \mathrm{~m} / \mathrm{s}$ [3]. Because of the high shear wave speed, acoustic waves are efficiently coupled into the shear mode if the sediment layer is sufficiently thin compared to a wavelength. The reflection coefficient for the layer is highly dependent on angle and the depth of the unconsolidated layer as shown in Figure 1. Here the sediment parameters are taken from reference [3].

Because the reflection coefficient is highly dependent on angle especially around 33 degrees as noted in reference [3], small changes in local topography can affect the bottom loss by $6 \mathrm{~dB}$ or more. Therefore, the propagation is likely to be highly dependent on the bathymetry and roughness of both the sand layer and the limestone. In this study, two effects on transmission loss are considered, the depth of the sand layer and the rough boundaries of the waveguide. The implications of these effects on inversion are discussed.

\section{Modeling}

\section{A. Geometric and geo-acoustic parameters}

The model parameters were chosen to mimic the measured data described in reference [3]. The parameters are given in Table I and Table II. Unlike the models from reference [3],

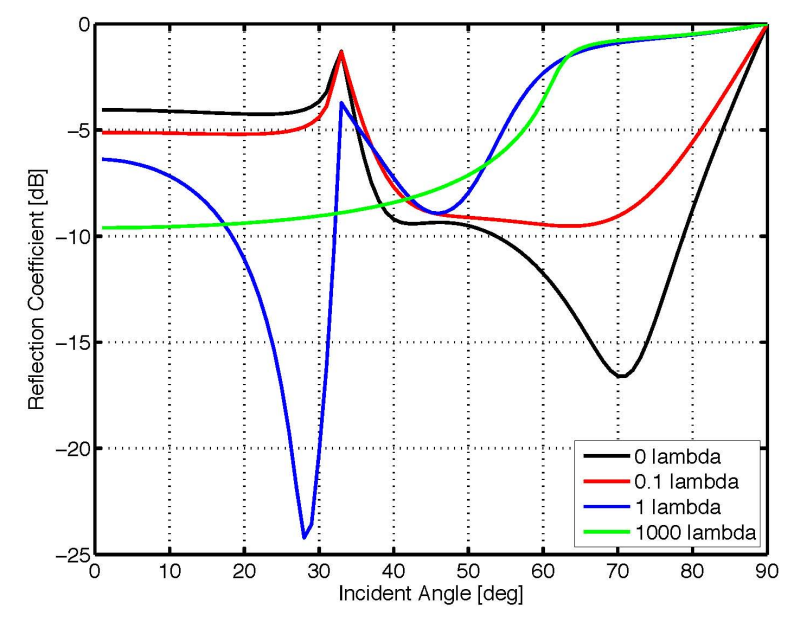

Fig. 1. The reflection coefficient for sand over calcarenite. As the sand layer depth grows with respect to an acoustic wavelength, the reflection coefficient is more like a sand half-layer. The sand reflection is higher at high incident angles. Note that the calcarenite has a large increase at around 33 degrees incident corresponding to the elastic mode.

only the calcarenite layer is considered, not the limestone basement. When considering sand layers, the depth from the air/water interface to the calcarenite will be kept constant at $42.5 \mathrm{~m}$. A 1.0 or $2.5 \mathrm{~m}$ sand layer is placed on top of the calcarenite.

Interface roughness is also included in the models. The air/water interface is characterized by the Pierson/Moskowitz spectrum with a $10 \mathrm{~m} / \mathrm{s}$ wind speed [5]. Measurements of interface roughness for sands has shown that the roughness spectrum is best described by the von Karman spectrum, described in reference [4]. This spectrum is a power law spectrum with a low frequency cut-off. The sand/calcarenite interface will also be described as a von Karmen spectrum with a high RMS roughness. Interface roughness parameters are given in Table I. 
TABLE I

MODEl CHARATERISTICS

\begin{tabular}{|l|c|}
\hline Parameter & Value \\
\hline Source Depth & $4 \mathrm{~m}$ \\
Water Depth & $42.5 \mathrm{~m}$ \\
Sand Depth & 1.0 or $2.5 \mathrm{~m}$ \\
Wind Speed & $10 \mathrm{~m} / \mathrm{s}$ \\
Water/Sand Interface RMS Height & $1.1 \mathrm{~cm}$ \\
Water/Sand Interface Power Law Exponent & 2.32 \\
Sand/Calcarenite Interface RMS Height & $32 \mathrm{~cm}$ \\
Sand/Calcarenite Interface Power Law Exponent & 2.32 \\
\hline
\end{tabular}

TABLE II

MATERIAL PARAMETERS

\begin{tabular}{|l|c|c|c|}
\hline Layer & Water & Sand & Calcarenite \\
\hline Compressional Speed $[\mathrm{m} / \mathrm{s}]$ & 1523 & 1700 & 2426 \\
Compressional Att. $[\mathrm{dB} / \lambda]$ & Francois-Garrison & 0.5 & 0.15 \\
Shear Speed & - & - & 1213 \\
Shear Att. $[\mathrm{dB} / \lambda]$ & - & - & 0.3 \\
Density & 1024 & 1800 & 2400 \\
\hline
\end{tabular}

\section{B. Flat Interface Model}

Both a flat interface model and a rough interface model are calculated. The flat interface model is calculated with the OAST module of the OASES suite [6]. OASES employs a wavenumber integration technique and calculates the depth dependent Green's function. It is much more efficient than the finite element (FE) model used to calculate the rough interface model described in the following section. OASES and finite element models were shown to provide the same transmission loss for waveguides with flat interfaces and elastic bottoms.

\section{Rough Interface Model}

To model the effects of interface roughness, a finite element analysis is performed. Finite element analysis is ideal for this problem since particular roughness realizations can be calculated. Two dimensional, time harmonic models will be calculated using the commercial code, COMSOL. The roughness realizations are calculated using the method described in reference [7]. Example of $100 \mathrm{~m}$ waveguides with the rough and flat interfaces are shown in Figure 2. The rough interface between the sand and the water appears flat on this scale. Shown on these figures is the calculated particle velocity norm. The waveguides consist of a source and a water layer over a $1.0 \mathrm{~m}$ sand layer with a calcarenite basement. The domains are truncated using perfectly matched layers [1]. These solutions are calculated at $300 \mathrm{~Hz}$. At this frequency, the particle velocity norm in the basement is much higher for the flat case especially directly beneath the source. For the rough case, much of the acoustic energy is scattered. Additionally, the air/water interface causes scattering near the top of the waveguide, leading to an asymmetric source beam pattern.

\section{RESULTS}

First, consider the effects of the sand layer without interface roughness. In Figure 3(a), the transmission loss as a function

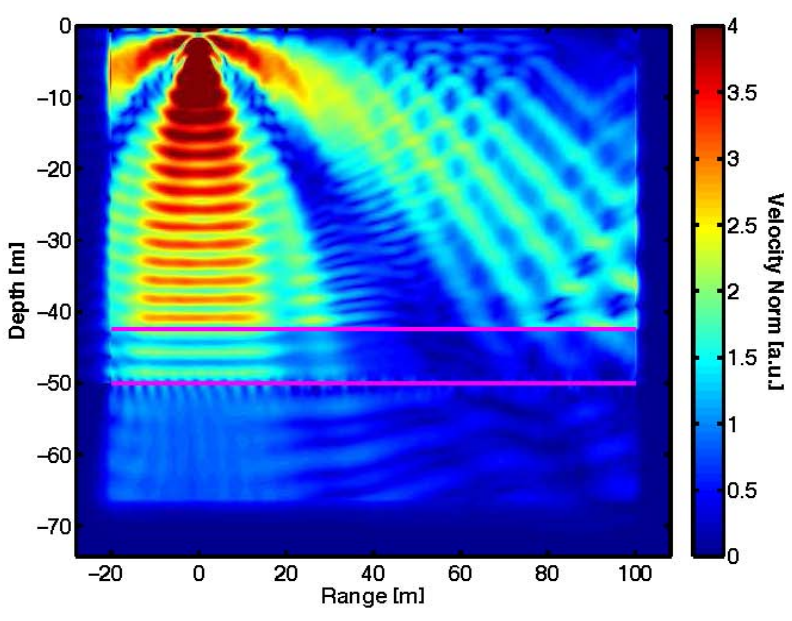

(a) Flat Domain

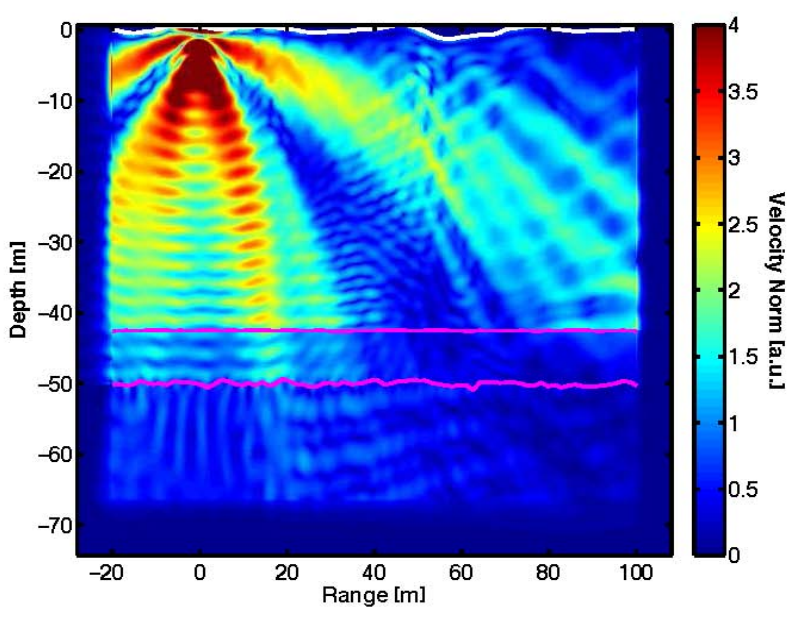

(b) Rough Interface Domain

Fig. 2. Finite element domains for the flat and rough interfaces displaying the particle velocity norm. The domains are truncated using perfectly matched layers. The rough air/water interface causes the source to have an asymmetric beam pattern. The roughness at the sand/calcarenite layer causes an increase in scattering at the interface. The rough sand/water interface is not noticiable on this scale.

of frequency and range is shown. The horizontal bands are due to the sharp spike in the reflection coefficient shown in Figure 1 and noted in reference [3]. In this case, the horizontal bands occur bands occur much higher in frequency than reference [3]. When a sand layer is introduced, there are two effects. First, the sand layer mitigates horizontal bands at higher frequencies, the effects of the elastic mode. In other words, the sharp spike in the reflection coefficient as shown in Figure 1 is reduced as the depth of the sand layer increases relative to the acoustic wavelength. Also the total energy in the waveguide is increased especially at longer ranges. This is due 
to the higher reflection coefficient at high incident angles as the depth of the sand layer increases relative to the wavelength.

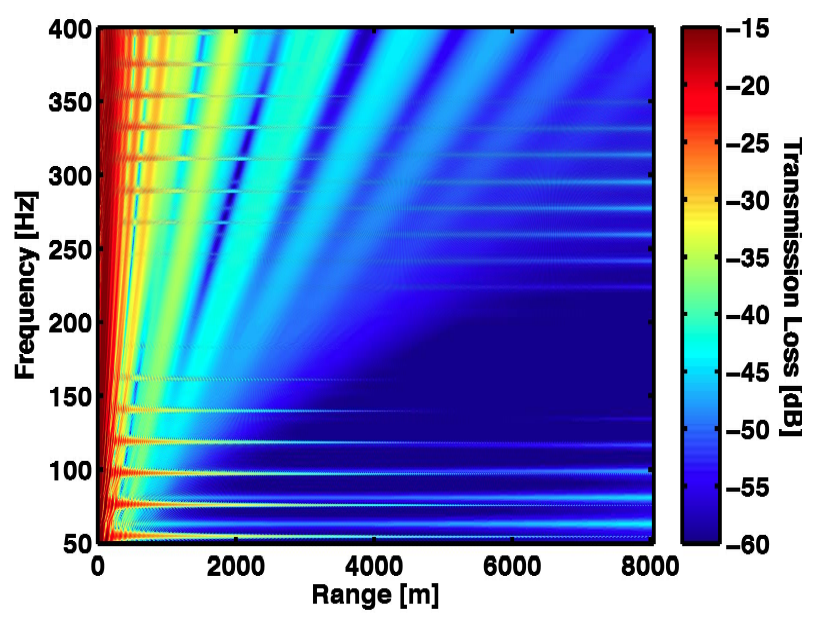

(a) No Sand Layer

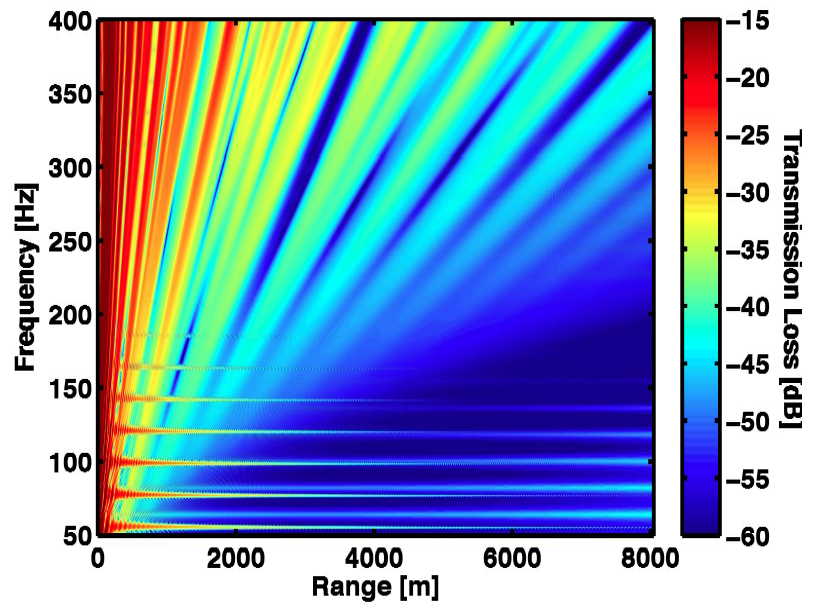

(b) $1.0 \mathrm{~m}$ Sand Layer

Fig. 3. Transmission loss in $\mathrm{dB}$ as a function of range and frequency for a bare calcarenite basement and calcarenite with a $1.0 \mathrm{~m}$ sand layer. The sand layer increases the amount of acoustic energy in the waveguide at higher frequencies due to the high reflection coefficient of sand at shallow angles. The horizontal bands are indicative of the spike in the calcarenite reflection coefficient at 33 degrees incident. At high frequencies, this is masked by the sand layer.

This effect is more noticeable when considering single frequency transmission loss curves. In Figure 4, the transmission loss for three frequencies is plotted for three cases: no sand layer, a $1.0 \mathrm{~m}$ sand layer and a $2.5 \mathrm{~m}$ sand layer. As the sand layer is increased, more energy is retained in the waveguide especially at longer ranges.

Lastly, as shown in Figure 4, a FE model of a $1.0 \mathrm{~m}$ sand layer is calculated with rough interfaces. (Note that only $2 \mathrm{~km}$ waveguides were computed using the FE method.) For low frequencies, such as $150 \mathrm{~Hz}$, the inclusion of roughness leads to an increase in the energy of the waveguide as some energy is scattered back into the waveguide. However, as the frequency increases, the roughness will allow a more efficient coupling into some of the elastic mode of the calcarenite. Essentially, with roughness, the local incident angle will cover more of the reflection curve allowing some coupling into the elastic mode even at far ranges. This leads to an increase of scattering into the basement and a decrease of energy in the waveguide. At $250 \mathrm{~Hz}$, the level of the transmission loss with $1.0 \mathrm{~m}$ roughness is close to that of the bare calcarenite.

Therefore, the rough interface model will mimic the bare calcarenite model at higher frequencies with respect to the total energy level. However, an inversion based on a bare calcarenite model will be incorrect since the frequency dependence and the modal interference pattern of the rough, sand layer model is different.

\section{CONCLUSION}

Much of the Southern and Western continental shelf of Australia consists of a calcarernite covered by a thin sand layer. Although it is simpler to model the bare calcarenite, the addition of a sand layer increases the energy of the waveguide dramatically at longer rangers by increasing the reflection coefficient at high incident angles. As the frequency increases, the energy is further increased as the sand layer becomes deeper with respect to the wavelength. However, adding roughness to the interfaces increases the scattering into the bottom. At long ranges, the rough interface can effectively couple energy into bottom acoustic modes by changing the local incident angle. Higher frequencies are more affected by the roughness as the surface appears rougher with respect to a wavelength.

For this case, at $250 \mathrm{~Hz}$, the transmission loss of a waveguide with a sand layer with rough interfaces is close to that of a flat bare calcarenite layer. However, an inversion based on a flat, bare calcarenite model would yield incorrect results because the modal interference pattern and the frequency dependence is different. Therefore, both the sand layer and the roughness should be considered if attempting inversions from this complex littoral region.

\section{ACKNOWLEDGMENT}

The authors would like to thank the Office of Naval Research, Ocean Acoustics for sponsoring this work.

\section{REFERENCES}

[1] J.P. Berenger. Perfectly matched layer for the FDTD solution of wavestructure interaction problems. IEEE Transactions on Antennas Propagation, 44:110-117, 1996.

[2] E.C.F. Bird. Geomorphology of the sea floor around australia. In J.R.V. Prescott, editor, Australia's Continental Shelf, pages 1-21. Nelson, 1979.

[3] L. Fan, A.J. Duncan, and A. Gavrilov. Propagation and inversion of airgun signals in shallow water over a limestone seabed. In Proceedings of the 3rd International Conference "Underwater Acoustic Measurements: Technologies and Results", June 2009.

[4] D.R. Jackson and M.D. Richardson. High-frequency seafloor acoustics. Underwater Acoustics. Springer Verlag, 2007. 
[5] L. Moskowitz. Estimates of the power spectrums for fully developed seas for wind speeds of 20 to 40 knots. Journal of Geophysical Research, 69(24):5161-5179, 1964.

[6] H. Schmidt. OASES Version 2.1 User Guide and Reference Manual. Department of Ocean Engineering, Massachusetts Institute of Technology, Cambridge, 1997.

[7] E.I. Thorsos. The validity of the Kirchoff approximation for rough surface scattering using a Gaussian roughness spectrum. Journal of the Acoustical Society of America, 83(1):78-92, 1988.

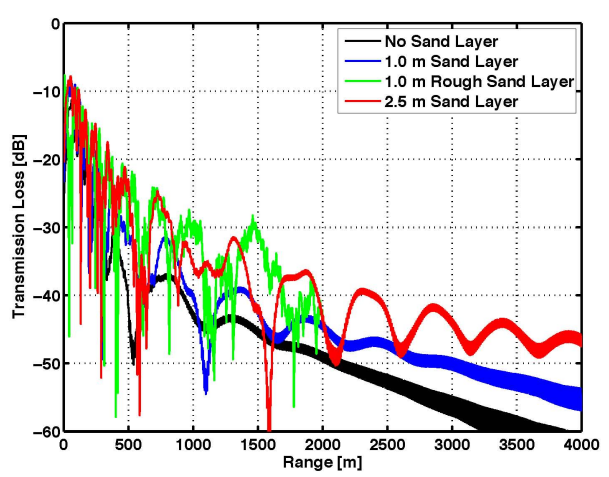

(a) $150 \mathrm{~Hz}$

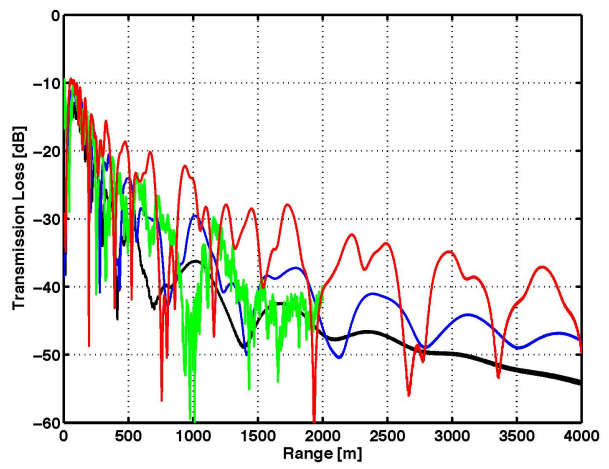

(b) $200 \mathrm{~Hz}$

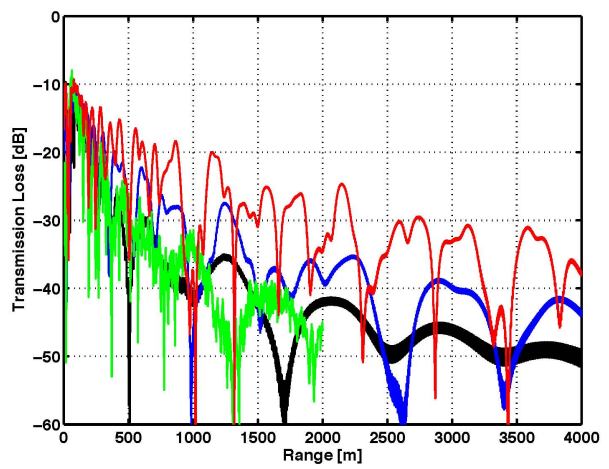

(c) $250 \mathrm{~Hz}$

Fig. 4. The transmission loss at three frequencies for four models: bare flat calcarenite, a flat $1.0 \mathrm{~m}$ sand layer over calcarenite, a flat $2.5 \mathrm{~m}$ sand layer over calcarenite, and a rough $1.0 \mathrm{~m}$ sand layer over a rough interface calcarenite The higher reflection coefficient of sand at high incident angles leads to less transmission loss at far ranges. The effect increases with frequency as the sand layer is deeper with respect to a wavelength. With rough interfaces, more energy is scattered. At higher frequencies, more energy is lost into the sediment and the transmission loss is consistent with the level consistent with bare calcarenite. 